Александрова-Осокина О. Н. Традиции семейной хроники в современной дальневосточной литературе / О. Н. Александрова-Осокина // Научный диалог. - 2021. — № 5. - С. $155-$ 168. - DOI: 10.24224/2227-1295-2021-5-155-168.

Alexandrova-Osokina, O. N. (2021). Family Chronicle Traditions in Contemporary Far Eastern Literature. Nauchnyi dialog, 5: 155-168. DOI: 10.24224/2227-1295-2021-5-155-168. (In Russ.).

\section{Традиции семейной} хроники в современной дальневосточной литературе

\section{Александрова-Осокина}

Ольга Николаевна

orcid.org/0000-0003-2960-9920

доктор филологических наук, доцент кафедра литературы и журналистики osokina-11@mail.ru

Тихоокеанский государственный университет (Хабаровск, Россия)
Family Chronicle Traditions in Contemporary Far Eastern Literature

\section{Olga N. Alexandrova-Osokina} orcid.org/0000-0003-2960-9920

Doctor of Philology, Associate Professor Departament of Literature and Journalism osokina-11@mail.ru

Pacific National University (Khabarovsk, Russia)

(C) Александрова-Осокина О. Н., 2021 


\section{ОРИГИНАЛЬНЫЕ СТАТЬИ}

Аннотация:

Рассматриваются вопросы содержания и жанровой поэтики произведений писателей-хабаровчан В. В. Сукачева («У очага») и Т. И. Гладких («Амурские казаки Кореневы»). Актуальность исследования обусловлена ценностью литературно-региоведческого материала для формирования целостной картины национального историко-литературного процесса. Новизна исследования состоит в том, что творчество названных авторов практически не изучено, а их сочинения, рассматриваемые в статье, впервые стали предметом литературоведческого анализа. Уделяется внимание тематике и проблематике произведений, раскрывающих трагические события отечественной истории XX века: депортация российских (крымских) немцев в 1941 году; послереволюционные судьбы амурского казачества. Представлен опыт анализа жанровой специфики произведений, соединяющих семейную хронику, притчу, беллетризованную биографию, мемуары. Сравнительно-сопоставительный анализ произведений позволил выявить общность организации сюжетно-композиционных элементов, присущих жанру семейной хроники. Особое внимание уделяется специфике авторского подхода к художественной обработке историко-биографического материала (способы эстетизации и беллетризации документального материала, воплощения образа автора, описания судеб поколений, создания образа «родоначальника», использование символики). Обосновывается мысль о том, что произведения утверждают абсолютную ценность человеческой личности.

\section{Ключевые слова:}

Сукачев Вячеслав Викторович; Гладких Татьяна Иннокентьевна; литературная регионалистика; семейная хроника; документально-художественные жанры.

\section{ORIGINAL ARTICLES}

The questions of the content and genre poetics of the works of the Khabarovsk writers V. V. Sukachev ("At the hearth") and T. I. Gladkikh ("Amur Cossacks Korenevs") are considered. The relevance of the study is due to the value of the literary and regional studies material for the formation of a holistic picture of the national historical and literary process. The novelty of the research lies in the fact that the work of the named authors has practically not been studied, and their works, considered in the article, for the first time became the subject of literary study. Attention is paid to the themes and problems of the works that reveal the tragic events of the national history of the twentieth century: the deportation of the Russian (Crimean) Germans in 1941; post-revolutionary fate of the Amur Cossacks. The experience of analyzing the genre specificity of works connecting family chronicle, parable, fictionalized biography, memoirs is presented. Comparative analysis of the works made it possible to reveal the commonality of the organization of plot and compositional elements inherent in the genre of family chronicles. Particular attention was paid to the specificity of the author's approach in the artistic processing of historical and biographical material (methods of aestheticization and fictionalization of documentary material, the embodiment of the author's image, describing the fate of generations, creating the image of the "ancestor", the use of symbolism). In the process of analysis, the idea was substantiated that the works have a pronounced value component, asserting the absolute value of the human person.

Key words:

Vyacheslav Sukachev; Tatiana Gladkikh; literary regional studies; family chronicle; documentary and artistic genres. 


\section{Традиции семейной хроники в современной дальневосточной литературе}

\section{С Александрова-Осокина О. Н., 2021}

\section{1. Введение. Семейная хроника как литературный жанр: жанрово- стилевые черты и опыт изучения}

Настоящая статья, представляя творчество писателей-хабаровчан В. В. Сукачева [Библиотеки Комсомольска; Литературный портал] и Т. И. Гладких [Журнальный мир], вносит вклад в масштабную работу по изучению литературной жизни российского Дальнего Востока. Вопросы литературной регионалистики сегодня активно разрабатываются: историко-культурные процессы России невозможно полноценно отразить без учета «областных культурных гнезд» (Н. К. Пиксанов), — однако обширность проблемы все еще оставляет богатое пространство для исследований.

Предметом изучения в настоящей статье являются повесть «У очага» В. В. Сукачева (2006) [Сукачев] и «документальное повествование» «Амурские казаки Кореневы» Т. И. Гладких (2017) [Гладких, 2017]. В первом произведении рассказывается о депортации российских немцев из Крыма в Казахстан в 1941 году; во втором - о судьбе амурского казачьего рода Кореневых в конце XIX - первой половине XX веков. Произведения изучаются как семейные хроники; цель исследования - выявить особенности жанрово-стилевого воплощения и осмыслить созданную авторами художественно-философскую концепцию семьи.

В современном литературоведении параметры жанра семейной хроники достаточно детально описаны. Семейная хроника «отражает вписанность человека в метаисторический контекст и представление о метафизичности истории, о связях с родом, с бытием, Богом, памятью» [Ащеулова, 2013, с. 48]. Произведения этого жанра воссоздают историю нескольких поколений, прослеживают связь семейной жизни с эпохальными событиями; в них социально-историческое показано через призму семейно-биографического; такие категории, как «время», «история», «род», становятся самостоятельными предметами художественного осмысления наряду с судьбами героев [Ащеулова, 2013; Евдокимова и др., 2017; Николаева, 2004; Никольский, 2020; Самофалова, 2015; Эпштейн, 1975].

«Память» и преемственность поколений в семейной хронике являются ценностными и сюжетообразующими категориями; цель хроники - сохранить события истории для будущих поколений; «эти произведения соз- 
даются писателями именно для того, чтобы <..> доказать, что главные катаклизмы позади и жизнь продолжается, несмотря на трагические и драматические коллизии» [Никольский, 2020, с. 50]. Центральным в структуре хроники является образ дома, топоса «родового гнезда», с которыми рассказчик связывает начала своей личности, см., в частности, [Самофалова, 2014; Никольский, 2020].

В системе героев семейной хроники обязательно присутствие «родоначальника», который составляет «смысловую пару» с потомком - ребенком, воспринимающим семейные предания, сохраняющим родовую память и выступающим «летописцем» рода. Автор хроники декларирует задачи своего творчества - сохранение памяти для потомков и осмысление собственного места в истории рода [Евдокимова и др., 2017, с. 16].

Определение места «документальной» и «художественной» хроники в системе документально-художественных жанров имеет два подхода. Некоторые ученые, например Е. В. Никольский, в рамках этого жанра рассматривают только художественные, романные, произведения; другие исследователи, в частности, О. В. Евдокимова, Е. А. Самофалова, Н. А. Николаева, относят сюда также мемуарную и документально-художественную прозу. Включение мемуарной документальной литературы в этот ряд видится оправданным: говоря словами Л. Я. Гинзбург, «искусство не отделено наглухо ни от логического познания, ни от жизненных фактов <..> В промежуточных, например, автобиографических и биографических жанpax, <..> порой особенно обнаженно выступают принципы понимания человека» [Гинзбург, 1976, с. 8], факты самой жизни часто оказываются богаче художественного вымысла, несут в себе скрытую энергию значений и смыслов [Там же, с. 16].

В дальневосточной литературе традиции семейной хроники нашли воплощение в исторических романах советской эпохи (А. А. Фадеев «Последний из Удэге», Н. П. Задорнов «Амур-батюшка», Г. Г. Ходжер «Амур широкий», Дж. Кимонко «Там, где бежит Сукпай»). Основной конфликт этих произведений типичен для исторической литературы соцреализма (социальные противоречия внутри рода, разрушение патриархального уклада, утверждение нового социального опыта); региональной спецификой этих романов стало изображение быта и культуры коренных народов Приамурья.

В документально-художественных произведениях В. В. Сукачева и Т. И. Гладких, написанных уже в XXI веке, отражен современный взгляд на события отечественной истории XX века. Обусловленным видится и документальная форма: интерес к документу в литературе обостряется именно в напряженные периоды истории [Местергази, 2007]. 


\section{2. Повесть В. В. Сукачева «У очага»: трагедия народа сквозь призму истории одной семьи}

Автобиографическая повесть «У очага» рассказывает о судьбе крымских немцев, депортированных в 1941 году в Северный Казахстан. Эта тема освещается в литературе последних лет [Зейферт, 2017], однако широкому читателю она все еще мало известна. В творчестве В. В. Сукачева эта тема находит отклик в автобиографических повестях «У самого синего моря», «Подлетыши», «Белые птицы детства».

В повести «У очага» прослеживается история трех поколений: главной героини Амалии Бауэр (бабушки главного героя, «родоначальницы»); ее внука (автобиографического героя в детстве), воспринимающего ее рассказы; и автора-повествователя, осмысливающего историю бабушки и свое детство уже из современности. Судьба страны и судьба семьи выступают в неразрывном единстве. Обозначенные в произведении временные границы связаны с веховыми датами в истории России. Первая: это начало Великой Отечественной войны и депортации; второй период связан с 1957 годом - началом «оттепели»; и наконец, третья временная веха это современность, начало XXI века (время, связанное со сменой мировоззренческой модели в послеперестроечный период).

В основе сюжетно-композиционного построения повести - ретроспекция: автобиографический герой (автор) вспоминает свое детство и разговоры с бабушкой, в которых та в свою очередь вспоминает о событиях депортации 1941 года. Таким образом, композиция повести объединяет три хронотопа, связанных с тремя типами героев: бабушки (старшее поколение), ребенка (автора в детстве) и автора-повествователя (современность). С каждым из них связан свой характер мировосприятия и своя повествовательная манера. Связь всех нарративных элементов мотивирована, складывается в целостную художественную систему, в которой память оказывается главной ценностной и сюжетообразующей категорией. Оперируя словами М. М. Бахтина, можно сказать, что архитектоника повести «строится вокруг человека-героя» и реализует заложенную в мысли автора энергию «внепространственно-вневременной бесконечности» [Бахтин, 2000, с. 10].

У каждого из трех названных персонажей свой «исторический суд», обусловленный временной и личностной дистанцией, жизненным опытом и соотнесенностью с различными историко-культурными и ценностными реалиями.

Основа повести документальна: здесь приведены реальные имена членов семьи (Амалия Бауэр, Иван Сукачев - дед и бабушка автора), географические названия (Фриденталь; Мамлютка, Бескамышка); факты из семейной истории (странствие из Крыма в Северный Казахстан, жизнь на новом месте, обвинение бабушки Амалии Бауэр во вредительстве и т. д.). 
На примере одной семьи показано, что депортация стала эпохальным событием для целого народа, бесповоротно изменила судьбы семей, навсегда лишила людей связи с родной землей, разрушила полностью семейный уклад, повлекла за собой смерти близких.

История жизни в рассказах Амалии Бауэр, хотя и является «воспоминанием», ретроспекцией, в ценностной системе героини не имеет временной дистанции, исторические события раскрываются в личностном измерении; рассказ окрашен страданием, горечью памяти о трагических событиях, а прошлое предстает как череда несправедливостей, жестокостей, страданий. «Исторический суд» Амалии Бауэр не имеет снисхождения и прощения, время «не залечило» ее память; ее рассказы являются обвинениями в искалеченной жизни.

Образ ребенка (автобиографический герой, автор «в детстве») связан с другой системой психологического восприятия и ценностного видения. Детству присуще наивное, идиллическое мировосприятие: страшная историческая правда, рассказанная бабушкой, оказывается для него семейным преданием, которое «пугает», «расстраивает», но не определяет характер детского мироощущения; детское сознание не может в полной мере оценить масштаб беды. Доминирующим для ребенка является чувство защиты, любви, тепла домашнего очага; зло в сознании ребенка видится в разрушительном, но преходящем виде, а добро - в его вечной, неуничтожимой ипостаси.

Повествование, связанное со сферой автора-повествователя, - третий содержательно-смысловой уровень повести - имеет уже выраженную медитативную природу, это авторский лирико-философский монолог, содержанием которого становится не сюжетно-событийный ряд, но авторские размышления о путях истории, о месте человека в исторических процессах, о ценности человеческой жизни. Композиционно пространство авторского текста предваряет и завершает сюжетное повествование, обрамляя его и определяя ценностно-смысловую парадигму для восприятия всего текста. Опорными становятся базовые образы-концепты, связанные с фундаментальными началами человеческой жизни: «вода», «огонь», «родник», «печь», «путеводная звезда».

Художественная структура повести сформирована этими тремя хронотопическими системами: бабушки, ребенка, автора, - переплетение их составляет целостное художественное пространство произведения.

Образ дома является ключевым в художественной системе повести, содержание этого образа связано с комплексом реальных значений (домжилье) и символико-метафорических (дом-защита, дом-судьба человека и т. д.). В хронотопическом мире трех названных героев повести образ дома получает различное семантическое наполнение. 
В мире Амалии Бауэр образ дома связан с разрушением мира. Начало странствия обусловлено потерей дома, а окончание - обретением его подобия на новом месте, обретением не «дома», а «пристанища». «Стали нас из домов собственных выгонять <..> и вот вылили мы со свочми чемоданами да узлами, дверь прикрыли, и все у меня внутри как захолонуло» - «ветрами продутая, сугробами по самые крыши занесенная североказахстанская деревня Бескамышка, где глубокой осенью 1941 года нашла приют депортированная семья моей мамыл» [Сукачев].

В рассказах героини прослеживается, как «дом» с комплексом составляющих его значений («уют», «тепло», «свет», «покой», «любовь», «единство») на всем протяжении «маршрута изгнания» связывается с разрушением или подменой, вместо дома люди получают «пристанище»: «крохотнылй вокзал, больше похожий на сарай»; «вагон смерти», «окаянный вагон», «погибель для сорока трех невинных душ», где «хуже, чем в аду»; свет заменяют «два крохотных оконца под самым потолком»; уют, пространство и тепло - теснотой и холодом: «нары в три яруса сколочены - вот и все удобства, <..>; в вагоне темнота, людей, как селедок в бочке, двери снаружи наглухо запертыл» [Там же]. «Дом» в рассказах бабушки не является «защитой»: так, например, сквозной в ее рассказе мотив страха («все позапуганные, дылить боимся», «мы в основном и молчали, ходили, как пришибленные, и помалкивали») распространяется и на мировосприятие людей в пространстве жилища: «радио говорит < .. > чересчур громко, потому что у него не предусмотрен регулятор громкости, а выдернуть вилку из розетки никто не решается: боимся, как бы потом чего не вышло» [Там же].

В мире ребенка, воспринимающего рассказы бабушки, напротив, мир дома связан с ощущением абсолютной защищенности. Лейтмотивом проходит противопоставление «внешнего холода» и «тепла дома»: «все никак не утихомирится разбушевавшаяся непогода $<\ldots>$ тоскливо подвывает ветер $\langle\ldots>$, да бьется о наши окна метель» — «скорее на печку, в это неповторимо уютное тепло» [Там же].

В мире ребенка образ дома соотносим с идиллическим пространством с присущими ему характеристиками «устойчивости», отграниченности от внешнего мира, абсолютности добра: тепло - это «всегда тепло», трапеза - всегда готова и «ждет» ребенка и т. д. «Прибежал я из школьл, одежду и валенки на широкую русскую печку побросал просушиться, и к столу поскорее - проголодался» [Там же]. Составляющими элементами образа «дома» являются мотивы домашнего разговора, понимания, единения, уюта.

Образ бабушки представлен как «ценностное ядро» домашнего пространства — это образ «родоначальника»: она является центром семейного опыта, «через нее» проходят исторические испытания; передавая свое ду- 
шевное тепло внуку, она оказывает созидающее и жизнеобеспечивающее начало для будущего своей семьи. В повести показано, что духовная преемственность не прерывается, несмотря на все испытания и несправедливости.

Тема семейно-родовой памяти связана с образом автора, хранящего и передающего в слове воспоминания о судьбе своей семьи. Взгляд автора на историю семьи соединяет бытовое и бытийное, выявляя вечные экзистенциальные смыслы человеческого бытия. Образ дома в этой системе - символ целостности поколений и абсолютной ценности человеческой жизни; содержанием образа становятся такие категории, как «устойчивость», «покой» («легко и покойно думается нам у огня»), «соединение противоположностей» (огонь и вода - «две стихии, извечно сопровождающие человека, породившие и выпестовавиие его», «сидим у тепло и уютно потрескивающего огненного родничка»); дом символизирует единство поколений, возможность диалога и понимания («рассказы моей бабушки < .. >всю жизнь будут для меня путеводной звездой»). Эти характеристики: устойчивость, устремленность в вечность, гармония - заставляют вспомнить о первоначалах человеческого бытия.

В этом контексте большую смысловую значимость приобретают и задачи творчества: это не просто желание рассказать о семейной истории, но более масштабная задача — сохранение памяти: «И вот, наконец, < ..> пришел тот час, когда я понял, что не могу и дальше носить в себе драгоченные зерна, оброненные в мою память в те далекие вечера, что пора поделиться всем усльлианным» [Там же]. Мотив зерна, брошенного в землю («в память»), имеет устойчивую семантику в Священных текстах и в целостном контексте повести связан с философским уровнем содержания произведения. Воспринимающий автобиографический герой осуществляет идею родовой памяти, преемственности поколений. А повесть, говоря словами М. М. Гиршмана, выступает как «воплотившаяся концепция мира и человека в их единстве» [Гиршман, 1982, с. 41]. Смысл повести оказывается смещен от рассказа о трагических событиях переселения к воспоминаниям о доброте родительского (в повести - дедушки и бабушки) дома, к размышлениям об устойчивости человека, о нравственно-ценностных основах бытия, позволяющих сохранять человеческое начало в нечеловеческих условиях.

\section{3. История России XX века в семейной хронике Т. И. Гладких «Амурские казаки Кореневы»}

В мемуарно-биографическом повествовании Т. И. Гладких «Амурские казаки Кореневы» собраны уникальные сведения о культуре русского казачества на Амуре. Книга имеет документальную основу: сюда вошли воспоминания, разговоры, письма, архивные документы, страницы из книги 
«На родной реке» В. С. Коренева - потомка рода Корневых, представителя русского литературного зарубежья. Пространство книги сформировано реальным географическим пространством и включает топонимику Приамурья (станица Поярково, Зея, Благовещенск), Китая (Харбин, Шанхай, Тянцзин), северных районов Амурской области (прииск Соловьевский, Уркан).

Автор не просто воссоздает факты семейной истории, но выстраивает бытие рода, связывая разрозненные события в единую картину и соотнося частное с эпохальным. «Было все: первые муравьевские сплавы, когда казаки из Забайкалья плыли на Амур, <..> потом войны и революиии, эмиграчия, ссылки, репрессии» [Гладких, 2017, с. 3]. История рода прослеживается с середины XIX века, с родоначальника - Тимофея Семеновича Коренева, основавшего династию на Амуре. Его сыновья упрочивали экономическую и культурную жизнь в Приамурье; были обладателями крупнейшей на Дальнем Востоке библиотеки, владельцами двух паровых мельниц, см. [Гладких, 2017, с. 14]. Новая ветвь рода Кореневых - «поколение внуков» - приняла на себя удар событий XX века: многие представители семьи оказались в изгнании («в их судьбах представлена вся география русской эмиграции в Китае» [Там же, с. 63]); оставшимся на Родине предстояло пройти через лишения и репрессии.

В композиции книги реализуются две метафоры: «фамильное древо» и «семейный альбом». История рода изложена последовательно, каждая глава посвящена одному человеку («Филипп Тимофеевич», «Симон Тимофеевич», «Тимофей Тимофеевич» и т. д.). Этот очерковый портретный материал в свою очередь собран в более крупные части, также названные по степени семейного родства («Сыновья», «Внуки», «Потомки казачьего рода» и т. д.).

Образы «род-дерево» и «семейный альбом» находят воплощение в художественной системе произведения («Кореневы, как большое, сильное дерево, корнями вросли в амурскую землю» [Там же, с. 16]); «Открываешь старый семейный альбом, как дверь в большую казачью избу <..> деды и прадеды, родители, дети, внуки, ближняя и дальняя родня - все они, неподвластные времени, собрались вместе, смотрят на нас из далекого прошлого» [Там же, с. 3].

В организации повести можно проследить внутреннюю связь с хроникально-летописным повествованием. Хроникальное начало связано с указанием дат семейных событий: женитьбы, поступления на учебу, выселения и т. д. Летописный тип повествования связан с задачей передать ощущение «необъятности исторического движения», предмет летописи не «один сюжет», но «русская история в ее целом», см. [Лихачев, 1979, с. 256]. Т. И. Гладких также выступает как «летописец», объединяя в своем произведении различные жизненные «документы» и восстанавливая целостность семейной 
памяти. В ее сознании эмпирический жизненный материал обретает ценностно-смысловое единство: «Mы по-разному постигаем прошлое. И хорошо, если история родной земли приходит через историю своего рода, своей семьи: тогда она как-то и теплей, и дороже, и ближе» [Гладких, 2017, с. 10].

Смысловым центром произведения является фигура основателя рода - Коренева Тимофея Семеновича; это «родоначальник», образ которого является семейной легендой; каждый член рода осознает свое родство с ним: «Прошло полтора с лишним века с тех пор, как забайкальский казак Тимофей Семенович Коренев поселился на Амуре, <...> Сегодня его потомки живут в разных местах России и за рубежом. Чаще всего мы давно носим другие фамилии, но помним, что вылии из одного старинного казачьего рода» [Там же, с. 3].

В описании дореволюционного прошлого семьи прослеживается идиллическое начало: жизнь показана в гармонии и патриархальных связях между членами семьи и между семьей и государством. Так, например, приамурский генерал-губернатор Н. И. Гродеков был крестным одного из детей семьи [Гладких, 1979, с. 36]; другой представитель рода - Тимофей Тимофеевич Корнев - за свои заслуги удостоен внимания будущего императора Николая Александровича Романова, в 1896 году в числе депутатов от Амурского казачьего войска приглашен на коронацию [Гладких, 2017, с. 30-31]. В картинах дореволюционной жизни подчеркнута связь с народной традицией: приводятся пословицы, поговорки, народные песни.

Создавая портретные характеристики, автор рисует мужчин рода как богатырей: "Даже внешне амурские казаки Кореневы вполне соответствовали смыслу своей фамилии. <...> все рослье, русые - как на подбор <... > На Амуре их называли семьей богатырей» [Там же, с. 6].

Образ прошлого показан как образ утраченного рая. Особенно «райская образность» ощутима в описании легендарного семейного сада: «B старые времена рос в Поярково замечательный сад. Заложил его еще сам основатель нашего рода Тимофей Семенович < .. > Сад был большой, чисто амурский: рядом с <..> грушами, яблонями мирно уживались пришельцьы тайги: липь, рябины, заросли душистой черемухи и акации вдоль забора. Была у дедушкина сада и своя чудесная особенность - его любили птиць. < ..> Звон стоял от их голосов ... <..> говорили, что примета такая есть: птицы прилетают к счастливыл» [Там же, с. 19].

О судьбе рода в послереволюционный период повествуется в двух разделах книги: «На Родине»и «На чужбине». Здесь представлена история постепенного рассеяния рода, испытаний, лишений, репрессий: «Иx cyдbбы уже были предопределены и вписаны в грядущую эпоху» [Там же, с. 52]; «Из четырнадцати внуков основателя династии десятеро оказались 
в Маньчжурии» [Там же, с. 61]. В описании жизни представителей семьи на Родине акцентирован момент страдальчества, невинной жертвы, аскетизма - и, таким образом, выделяется тема жертвенности в судьбе рода.

Актуализируя события и документы прошлого, автор выстраивает линию исторической и ценностно-смысловой преемственности между прошлыми поколениями и современностью. Семейно-родовая память становится основой для повествования о трагедии русского рассеяния в ХХ веке и о величии русской культуры, сумевшей сохранить себя в условиях репрессий и изгнания.

\section{4. Выводы}

Произведения В. В. Сукачева и Т. И. Гладких отразили драматические события отечественной истории XX века. Опровергая идею о вечном конфликте отцов и детей, авторы показывают духовную преемственность поколений, не растраченную даже в период исторических потрясений прошлого столетия. Духовными центрами произведений стали образы «родоначальников»: бабушки, Амалии Бауэр («У очага»), и основателя рода Коренева Тимофея Семеновича («Амурские казаки Кореневы»). Объединяющим в обоих произведениях является образ рассказчика, «хранителя семейной памяти»: «Семейное время <..> оказывается равным личной памяти семейного хроникера» [Самофалова, 2011, с. 107].

В повестях реализуется высказанная П. А. Флоренским мысль о значении памяти рода для самосохранения человека. Ученый видел род как неразделимое единство, целостно выполняющее свои жизненные задачи в истории: «Род — целое, а не сумма последовательных поколений <..> у кого нет рода, у того нет и Родины» [Флоренский, 1992, с. 419, 421].

Характер художественного переосмысления документального материала в произведениях различен. Повесть «У очага» тяготеет к мифопоэтическому мировосприятию: образы «огня», «воды», «очага» связывают современность с древними основами культуры. Ориентацию на бытийное начало подчеркивает данное автором жанровое определение «повесть-притча». Притча позволяет «охватить все бытие в целом, проникает в действие, которое, освободившись вследствие этого от условностей конкретной ситуации, завершается в своей отвлеченной многозначности, подобной иконическому изображению» [Базылев, 2020, с. 224].

Т. И. Гладких определила свое произведение как «документальное повествование». Определяя жанровую специфику произведения, мы считаем возможным использовать определение «беллетризованная биография». Эта форма в современных исследованиях определяется как «многослойный текст-палимпсест, где каждый компонент - аутентичные документы: 
фамильное древо, список источников, карты, фотографии, посвящения, эпиграфы» [Наумова, 2016, с. 237]. Все эти элементы присутствуют в повествовании Гладких; каждый привносит свои смыслы и значения в авторское произведение, наполняя текст духом эпохи. Произведение можно соотнести также с жанровой традицией мемуаров, здесь реализуются присущие этому жанру характеристики: установка на подлинность, «паспортизация» дат и событий, беллетризация фактов, публицистичность, субъективность повествования [Михайлова, 2015].

Изучение произведений В. В. Сукачева и Т. И. Гладких во всем многообразии их содержательной, ценностной и жанрово-стилевой специфики обогащает картину истории отечественной литературы новыми сведениями об особенности жанрового воплощения документально-художественных текстов.

\section{Источники}

1. Гладких Т. И. Амурские казаки Кореневы : документальное повествование / Т. И. Гладких. — Хабаровск : [б. и.], 2017. — 159 с. — ISBN 978-5-88570-409-0.

2. Библиотеки Комсомольска [Электронный ресурс]. - Режим доступа : https:// www.kmslib.ru/vyacheslav-viktorovich-sukachev-biografiya (дата обращения : 12.12.2020).

3. Журнальный мир [Электронный ресурс]. — Режим доступа : http://журнальныймир.pф/avtor/gladkih-tatyana (дата обращения 12.12.2020).

4. Литературный портал российских немцев [Электронный ресурс]. - Режим доступа : http://rd-autoren.de/allauthors/20-21-vek/20-21-sukatschjov-springer-wjatscheslaw. $\mathrm{html}$ (дата обращения 12.12.2020).

5. Сукачев В. В. У очага [Электронный ресурс] / В. В. Сукачев // Сайт Литературный портал российских немцев. - Режим доступа : http://rd-autoren.de/560-sukatschjovspringer-powestj-u-otschaga.html (дата обращения 12.12.2019).

6. Флоренский П. А. Детям моим. Воспоминанья прошлых дней ; Генеалогические исследования ; Из соловецких писем ; Завещание / П. А. Флоренский. - Москва : Московский рабочий, 1992. - 559 с.

7. Эпштейн М. Н. Хроника / М. Н. Эпштейн // Краткая литературная энциклопедия / гл. ред. А. А. Сурков. - Москва : Советская энциклопедия, 1962-1978. - Т. 8 : Флобер - Яшпал, 1975. - Стб. 333-334.

\section{ЛитеРАТУРА}

1. Ащеулова И. В. Семейная хроника как формирование исторической памяти поколений в романе В. Шарова «След в след» / И. В. Ащеулова // Вестник Томского государственного педагогического университета. — 2013. - № 2 (130). — С. 48-53.

2. Базылев В. Н. Притча : переосмысление жанра / В. Н. Базылев // Жанры речи. 2020. 一 № 3 (27). — С. 222-228.

3. Бахтин М. М. Автор и герой : К философским основам гуманитарных наук / М. М. Бахтин. - Санкт-Петербург : Азбука, 2000. — 336 с. - ISBN 5-267-00272-0.

4. Гинзбург Л. Я. О психологической прозе / Л. Я. Гинзбург. - Ленинград : Художественная литература, 1976. - 448 с. 
5. Гиршман М. М. Ритм художественной прозы / М. М. Гиршман. - Москва : Советский писатель, 1982. - $366 \mathrm{c}$.

6. Евдокимова О. В. Феномен семейной хроники в русской литературе XIXXXI веков : опыт описания / О. В. Евдокимова, А. С. Коматесова // Филологические науки. Вопросы теории и практики. - 2017. - № 6 (72) : в 3-х ч. - Ч. 3. - С. 16-19.

7. Зейферт Е. И. Хрестоматия прозы российских немцев второй половины XX начала XXI века на русском и немецком языках : актуальность, адресат, жанровый репертуар / Е. И. Зейферт // Вестник Российского университета дружбы народов. Серия : Вопросы образования : языки и специальность. - 2017. - Т. 14. - № 4. - С. 710 718. — DOI: 10.22363/2312-8011-2017-14-4-710-718.

8. Лихачев Д. С. Поэтика древнерусской литературы / Д. С. Лихачев. - Москва : Наука, 1979. - 360 с.

9. Местергази Е. Г. О термине «документальная литература» / Е. Г. Местергази // Вестник ТГУ им. Г. Р. Державина. — 2007. — № 11 (55). — С. 174-177.

10. Михайлова М. А. «Невымышленные рассказы» писателей XX в. : проблема синтеза художественного и документального в мемуарах «Нового мира» эпохи А. Твардовского [Электронный ресурс] / М. А. Михайлова // Вестник Вятского государственного гуманитарного университета. - 2015. — № 6. - С. 96-101.

11. Наумова О. А. Англоязычная беллетризованная биография последних десятилетий : мемуарно-художественная документальность и образы Сибири в «Истории Ольги» С. Вильямс / О. А. Наумова // Филология и культура. Philology and culture. - 2016. № 4 (46). - C. 237-242.

12. Николаева H. А. Трансформация жанра семейных записок XVIII-XIX вв. в «Семейной хронике» С. Т. Аксакова / Н. А. Николаева // Материалы к Словарю сюжетов и мотивов русской литературы. - Новосибирск, 2004. - Выпуск 6. - С. 64-82.

13. Никольский E. B. Романный субжанр семейная хроника : вопросы истории и теории (Статья первая) / Е. В. Никольский // ART LOGOS. - 2020. - № 3 (12). С. $50-65$.

14. Самофалова E. A. Жанровые признаки семейной хроники в женской мемуарно-автобиографической прозе второй половины XIX века : автореферат диссертации кандидата филологических наук : 10.01.01 / Е. А. Самофалова. - Москва, 2015. - 33 с.

15. Самофалова $E$. $A$. Семейная хроника как жанровый элемент воспоминаний / Е. А. Самофалова, Т. П. Пассек // Ученые записки : электронный научный журнал Курского государственного университета. — 2011. — № 4 (20). — С. 103-107.

\section{Material Resources}

Epshtein, M. N. (1975). Chronicle. In: Brief literary encyclopedia, 8: Flaubert-Yashpal. Moscow: Soviet Encyclopedia. 333-334. (In Russ).

Florensky, P. A. (1992). To my children. Memoirs of past days; Genealogical research; From the Solovetsky letters; Testament. Moscow: Moskovsky rabochy. 559 p. (In Russ).

Gladkikh, T. I. (2017). The Amur Cossacks of Korenev: a documentary narrative. Khabarovsk: [b. i.]. 159 p. ISBN 978-5-88570-409-0. (In Russ).

Journal World. Available at: http://журнальныймир.pф/avtor/gladkih-tatyana (accessed 12.12.2020). (In Russ).

Libraries of Komsomolsk. Available at: https://www.kmslib.ru/vyacheslav-viktorovich-sukachev-biografiya (accessed 12.12.2020). (In Russ). 
Literary portal of Russian Germans. Available at: http://rd-autoren.de/allauthors/20-21-vek/2021-sukatschjov-springer-wjatscheslaw.html (accessed 12.12.2020). (In Russ).

Sukachev, V. V. By the hearth. In: Site Literary portal of Russian Germans. Available at: http:// rd-autoren.de/560-sukatschjov-springer-powestj-u-otschaga.html (accessed 12.12.2019). (In Russ).

\section{REFERENCES}

Ascheulova, I. V. (2013). Family chronicle as the formation of the historical memory of generations in the novel. V. Sharov "Trace in the trace". Bulletin of the Tomsk State Pedagogical University, 2 (130): 48-53. (In Russ).

Bakhtin, M. M. (2000). Author and hero: to the philosophical foundations of the humanities. Saint-Petersburg: Azbuka. 336 p. ISBN 5-267-00272-0. (In Russ).

Bazylev, V. N. (2020). Parable: reinterpretation of the genre. Genres of speech, 3 (27): 222 228. (In Russ).

Evdokimova, O. V., Komatesova, A. S. (2017). The phenomenon of family chronicles in Russian literature of the XIX-XXI centuries: the experience of description. Philological Sciences. Questions of theory and practice, 6 (72) / 3. 16-19. (In Russ).

Ginzburg, L. Ya. (1976). On psychological prose. Leningrad: Khudozhestvennaya literature. 448 p. (In Russ).

Girshman, M. M. (1982). The rhythm of artistic prose. Moscow: Soviet writer. 366 p. (In Russ).

Likhachev, D. S. (1979). Poetics of Ancient Russian literature. Moscow: The Science. 360 p. (In Russ).

Mestergazi, E. G. (2007). About the term "documentary literature". Bulletin of the Derzhavin TSU named after G. R. Derzhavin, 11 (55): 174-177. (In Russ).

Mikhailova, M. A. (2015). "Non-fictional stories" of writers of the XX century: the problem of synthesis of fiction and documentary in the memoirs of the "New World" of the era of A. Tvardovsky. Bulletin of the Vyatka State University for the Humanities, 6: 96-101. (In Russ).

Naumova, O. A. (2016). English-language fictionalized biography of the last decades: memoirartistic documentary and images of Siberia in the "History of Olga" S. Williams. Philology and Culture. Philology and culture, 4 (46): 237-242. (In Russ).

Nikolaeva, N. A. (2004). Transformation of the genre of family notes of the XVIII-XIX centuries in the "Family chronicle" of S. T. Aksakov. Materials for the Dictionary of plots and motives of Russian literature, 6. Novosibirsk. 64 -82. (In Russ).

Nikolsky, E. V. (2020). Roman subgenre family chronicle: questions of history and theory (Article one). ART LOGOS, 3 (12): 50-65. (In Russ).

Samofalova, E. A. (2011). Family chronicle as a genre element of memories. Scientific notes: electronic scientific journal of Kursk State University, 4 (20): 103-107. (In Russ).

Samofalova, E. A. (2015). Genre signs of family chronicles in women's memoir-autobiographical prose of the second half of the XIX century. Author's abstract of PhD Diss. Moscow. 33 p. (In Russ).

Zeifert, E. I. (2017). Anthology of prose Russian germans second half of the XX — beginning of the XXI century in Russian and German: relevance, addressee, genre repertoire. Bulletin of the People's Friendship University of Russia Series: Questions of education: languages and specialty, 14 (4): 710 - 718. DOI: 10.22363/23128011-2017-14-4-710-718. (In Russ). 